\title{
CORRESPONDENCE
}

\section{EU innovation must benefit society}

The narrow focus on innovation in preparation for the next European Framework programme is steering environmental and health research in the wrong direction (Nature 473, 421; 2011).

Although these fields do not promise immediate economic growth, they are crucial drivers of innovation, focusing on complex socioecological systems, stimulating technological solutions and providing the basis for the sustainability of all innovations.

The European Union's (EU's) 2020 strategy brands the 'Innovation Union' as essential for "smart, sustainable and inclusive growth". This carries the risk that growth, competitiveness and innovation will be taken as ends per se, ahead of human well-being and sustainability. It is worryingly similar to the dominant approach before the economic crisis - one that led to unsustainable use of resources, crippling biodiversity loss and increased greenhouse-gas emissions.

Innovation is not an end, but a means to promote sustainability, human health and well-being. We must target European innovation discourse, policies and actions towards socially meaningful innovation. Technological and ideological lock-ins will not solve economic, societal and environmental crises. Sustainability requires transformation in all spheres (see go.nature.com/rmd44g).

This week in Brussels, the European Commission holds its conference on the Common Strategic Framework for EU Research and Innovation Funding. The European research policy is a powerful tool for shaping "an economy with a human purpose" (R. Passet Le Monde Diplomatique, February 2001). The EU should not pass up this historic opportunity. Sybille van den Hove Median, Barcelona, Spain. sybille@median-web.eu Jacqueline McGlade European Environment Agency, Copenhagen, Denmark.

Michael H. Depledge Peninsula Medical School, University of Exeter, UK.

\section{NIH: translation centre bridges a gap}

We disagree with Henry Miller that the US National Institutes of Health (NIH) should abandon plans to establish NCATS, the National Center for Advancing Translational Sciences (Nature 472, 169; 2011).

Researchers in academia all too often lack access to drug-discovery infrastructure, hindering translation of NIHfunded basic research into new medicines. Although the pharmaceutical industry may step in, it tends to ignore disease types that it considers too risky.

NCATS would allow NIHfunded researchers to create proof-of-concept compounds for neglected-disease targets and biomarkers for drug development, and even to launch early-stage clinical studies. Such 'de-risked' projects would offer in-licensing opportunities for drug firms. The non-profit research community should also benefit (A. J. Stevens et al. N. Engl. J. Med. 364, 535-541; 2011).

Contrary to Miller's view, "government bureaucrats" will not decide which drugs to pursue. NIH programmes slated to move into the NCATS involve researchers at universities, hospitals and institutes, mostly using peer review to allocate funding.
The public is frustrated by the slow translation of basic research into clinical benefits. Venture investors and biotechnology companies are exacerbating this by replacing early-stage research and development with product in-licensing.

John C. Reed ${ }^{\star}$ Sanford-Burnham Medical Research Institute, California, USA. jreed@sanfordburnham.org E. Lucile White ${ }^{\star}$ Southern Research Institute, Alabama, USA. ${ }^{*}$ On behalf of 5 co-signatories (see go.nature.com/lcvnnw).

\section{NIH: FDA key for speed and safety}

The US National Institutes of Health (NIH) and the Food and Drug Administration (FDA) should work together to bring products to market (Nature 471, 135; 2011). A telling example reveals how well this can work.

In the early 2000s, the National Institute of Child Health and Human Development conducted clinical trials of $17 \mathrm{P}$, a drug that successfully reduced pre-term birth by more than $30 \%$ in women who had experienced it previously (P. J. Meis et al. N. Engl. J. Med. 348, 2379$2385 ; 2003)$. The FDA granted the drug orphan status in 2003 to motivate the pharmaceutical company behind 17P to apply for FDA approval, which was granted this year after using the same NIH trial for the approval process.

In the interim, compounding pharmacies sold the drug at about US $\$ 400$ per course of treatment. Some insurance companies chose not to pay for it because the drug was not FDA approved, which increased their later spend on complications from preterm births that could have been avoided.

With 17P approved and protected from competition for 7 years, the pharmaceutical company raised the drug's price to $\$ 30,000$ and sent stern letters to pharmacies. In a later announcement of FDA drugenforcement priorities, $17 \mathrm{P}$ was low on the list because no safety issues had been reported regarding pharmacies.

This breakthrough would not have occurred had the NIH not focused on solving the costly and complex issue of preterm birth, or without the FDA having granted orphan status and publicly announcing its enforcement priorities.

James P. Reichmann American HomePatient, Tennessee, USA. jim.reichmann@ahom.com

\section{Slovenian scientists reward mentors}

Inspired by Nature's Mentoring Awards (Nature 471, 547; 2011), the Society of Young Researchers of Slovenia is recognizing the country's research mentors with its own award (see go.nature. com/hiddyb).

The society made the first call for nominees in 2009 after gathering information about good mentoring practices and lobbying for support from Slovenia's research institutes and funding bodies. The response exceeded expectations, with 32 nominations for 26 nominees (about 800 mentors were eligible). Nominations remained steady in 2010 (24 nominations and 22 nominees) and more institutions were represented.

Developing and promoting the initiative has paid off. Several prominent research institutions and government bodies, as well as many individual mentors, have expressed their support. Anže Županič ${ }^{\star}$ Newcastle University, UK. anze.zupanic@ncl.ac.uk ${ }^{\star}$ On behalf of 17 co-signatories (see go.nature.com/3a2mwj). 